\title{
Theoretical Investigation of Multi Axis Tipper Design
}

\author{
Iftikarahamad H. Patel ${ }^{1}$, Tushar M. Mudhe ${ }^{2}$, Prasad M. Sherkar ${ }^{3}$, Nilesh N. Saykar ${ }^{4}$, Dinesh S. Pendawale ${ }^{5}$ \\ Assistant Professor, Mechanical Engineering Department, Shivnagar Vidya Prasarak Mandal's C. O. E. Malegaon (bk), \\ Baramati, India ${ }^{1}$
}

Graduate Student, Mechanical Engineering Department, Shivnagar Vidya Prasarak Mandal's C. O. E. Malegaon (bk),

Baramati, India ${ }^{2,3,4,5}$

\begin{abstract}
Tipper has lots of applications in daily life of human being. In industrial and domestic considerations, tippers can pull a variety of products including gravel, grain, sand, fertilizer, heavy rocks, etc. By considering wide scope of the topic, it is necessary to do study and research on the topic of tipper mechanism in order to make it more economical and efficient. In existing system, tipper can unload only in one side by using pneumatic jack or conveyor mechanism. By this research, it is easy for the driver to unload the trailer in three sides and also it reduces time and fuel consumption. For making tipper mechanism with such above conditions pneumatic jack mechanism can be used. This paper has mainly focused on above difficulty. Hence a prototype of suitable arrangement has been designed. The vehicles can be unloaded from the trailer in three axes without application of any impact force. The Direction control valves which activate the ram of the pneumatic cylinder which lifting the trailer cabin in require side. By this research it is easy for the driver to unload the trailer and it reduces the time.
\end{abstract}

Keywords: Pneumatic cylinder, Ball socket joint, Hinge joint, Stepper motor, Spur gear.

\section{INTRODUCTION}

A trailer is a vehicle designed for carrying bulk material, often on building sites. A trailer is an integral part of any construction work and hence its role is important for completion of any constructional site. One of the problem are cited with trailer in the time and energy for setting the huge trailer in proper direction to dump the material it in carrying.

Nowadays trailers unloads in only one direction. Existing trailers requires more space, time and fuel as so to overcome these problems we want to introduce the three way tipper mechanism so that the device is economical and efficient. This tipper mechanism can do a great job by unloading the goods in three direction This tipper mechanism generally relates to ball socket joint for unloading the material in back side, left side or in right side direction by the use of pneumatic cylinder. The ball socket joint is used to provide motion in three direction. To unload the material in right side or in left side, we have fix the one side by hinge joint using pin. In this project the pneumatic cylinder is attached below whole trolley setup and this pneumatic cylinder's bottom end is mounted on disc and it rotated by using gear arrangement and stepper motor. This tipper mechanism is used to lift the trolley for unloading the material in different directions. This tipper mechanism can be applied to both domestic as well as industrial area. The proposed mechanism used for unloading purpose is safe and efficient and could be used safely in different areas.

\section{LITERATURE REVIEW}

Amboji Sudhakar R., Humane Yogesh A., Chavan Rohan R., Patil Jyotsna C., Kshirsagar Prashant R. et. al. [1] in India studied the 'Modern three way dumping tipper', which has been conceived by observing the difficulty in unloading the materials. They mainly focusing on this difficulty. Hence prototype of suitable arrangements has been designed. For making tipper mechanism hydraulic jack is used. After carrying out the testing of mechanism they got a positive result like they have able to increase the easiness in unloading the trolley.

Ganesh Shinde, Prachi Tawele and Laukik Raut et. al. [2] studied the dumping system. This study regards several automobile garages revealed the facts that mostly some difficult methods were adopted in unloading the material from the trailer. Hence develop a model in which three individual hydraulic cylinders was used. Power for operating the pump is taken from engine. The developed prototype exhibits the expected results. Further modifications and working limitations will put this work in the main league of use.

This concept saves time \& energy which leads to efficient working. This further line should be modelled using equations and an experimental agreement. The constructional work or the infrastructural work demands efficient and user friendly machinery which will lead to more and more use of three way dropping dumper. But in this system three cylinder as well as six hoses are required hence system is costly and complicated. 


\section{IARJSET}

M. Abul Rahaman, R. Dharmarajan, G. Dileepan, S. and air reservoir tank. Locking arrangement is given to Dinesh, R. Lingeshwaran et. al. [3]studied the multi axis unlock the remaining two side while unloading in one tipper mechanism by observing present system, there was side. a limitations that if the tipper should unload by its different sides. In order to overcome this difficulty they introduce the multi axis tipper mechanism that can lift the tipper carriage on the entire three axis with the help of simple locking system on the entire three axis. It uses the concept of normal hydraulic system with the use of hydraulic cylinders.

S. Srinivasan, P. Sivanesh, G. Sugavaneswaran, K. Muthukoori, et. al. [4] studied the downloading mechanism using three degree of freedom in truck trailer. They survey in the regard in some difficult method were adopted in unloading the materials from trailer. The trailer will unload the material in only one single direction. It is difficult the unload the material in small compact streets and small roads.

In their project this are rectified to unload the material in all three directions very easily. They concentrate on this difficulty and hence suitable arrangement has been designed. In their mode three hydraulic cylinder are used to unload the trolley in three sides. The developed prototypes of their concept exhibits the expected results.

N. Eswara Prasath, S. Shanmugam, C. Mathalai Sundaram , A. Vembathu Rajesh et. al. [5] studied the three side lifting trailer mechanism by observing the difficulties in unloading the materials from trailer. In a existing system, tipper can unload only in one sides by using pneumatic jack or conveyor mechanism. They mainly focus on this difficulty. Hence suitable arrangement for unloading the material in different direction is developed. In their system they uses single hydraulic cylinder for lifting the trailer.

The vehicles can be unloaded from the trailer in three axis without application of any impact force. The direction control valves which activate the ram of the hydraulic cylinder which lifting the trailer cabin in required side. The developed prototype exhibits the expected results.

\section{CONSTRUCTION}

In multi axis pneumatic tipper, tipper body is constructed by using material like MS sheet, MS square pipe, etc. In this tipper, there are some major parts from that one is air compressor. Air compressor is positive displacement type and run with help of electric motor. Reservoir tank is used to store the compressed air, which is transferred to the pneumatic cylinder. Other part of trailer body mounted on chassis with some specific support arrangement in that spur gears, stepper motor, disc,shaft,bearing etc. Stepper motor consist of driver gear and driving gear is mounted on rotating shaft, between the rotating disc and midpoint of trailer body the pneumatic cylinder is fixed. From the reservoir tank, high pressure supplied to the direction control valve. DCV and FCV is in between the cylinder
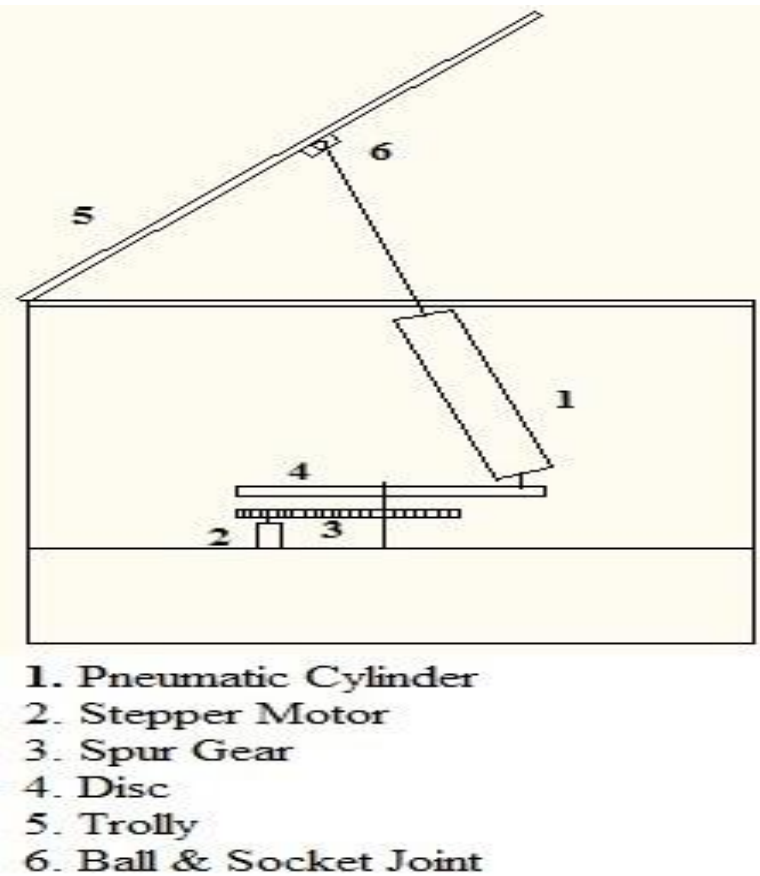

Fig.1 Working model of multi axis tipper

\section{WORKING}

The material unloading process is done in three axis with the help of locking arrangement and pneumatic system. The compressed air is going to the pneumatic cylinder through the direction control valve and flow control valve. The direction control valve is used to control the flow direction of the pneumatic cylinder in both the direction and flow control valve is used to control the flow of fluid towards cylinder. The pneumatic cylinder is mounted on the rotating disc with locking arrangement of trailer. The stepper motor and rotating disc with cylinder are used to operate the trolley operations in various axis. The high pressure compressed air is given to the pneumatic cylinder in piston side through meter-in-circuit when the knob is moved to position I of $5 / 3 \mathrm{DCV}$. The air pushes the pneumatic cylinder piston and move forward. The piston moves towards the upward direction and the trailer body is lifting the cabinet upwards and material is unloading in one direction by help of locking arrangement. The knob of direction control valve is moved to position III then air given to cylinder in rod side and piston moves towards downwards, air in piston side escape to atmosphere. Initially trailer is attached with the air compressor and reservoir tank to $5 / 3$ direction control valve which is the source of pressurized air for pull/push of pneumatic cylinder. After that this direction control valve is attached to pneumatic cylinder. As a result of which pneumatic cylinder can operate smoothly in both revered and forward direction. 
IARJSET

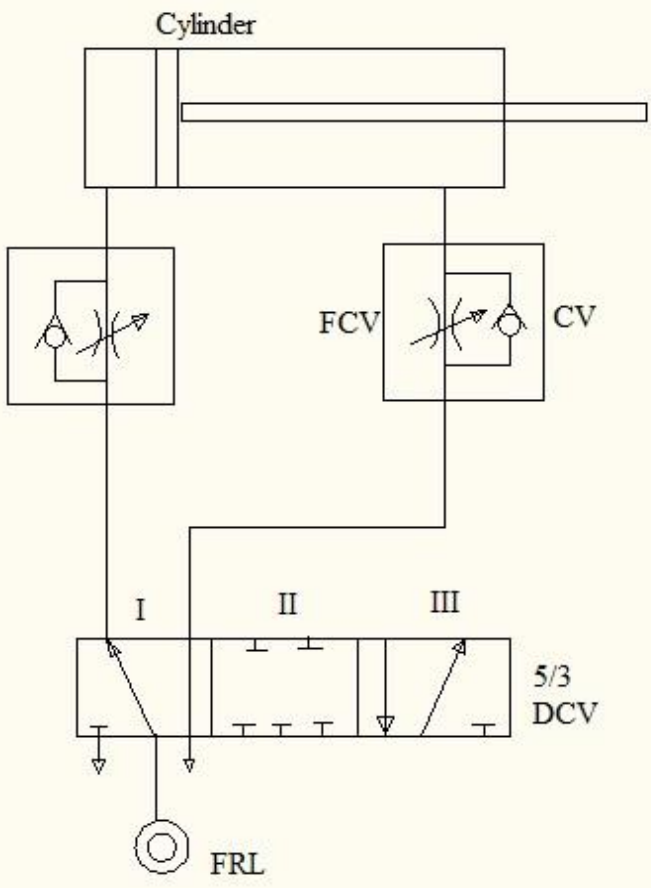

Fig.2 Pneumatic Circuit of Tipper

The Pneumatic Cylinder is Mounted on the rotating disc with tiled angle of 60 degree which is rotated with the help of gear assembly and a motor, with the help of which cylinder is rotated in 180 degree to unload material in three direction. The 2nd end of cylinder is fixed at the centre of trailer with the help of ball and socket joint. When unloading of material is done in another axis then direction of cylinder change with the help of rotating disc and stepper motor. The direction in which unloading is done, that side of trailer is locked by using locking pin for unlocking other two side.

\section{DESIGN}

In this paper we are designing trailer for assumed load Assumed load,

$\mathrm{M}_{1}=100 \mathrm{~kg}$

The total load i.e load for which we are designing trailer and load of trolley material

Mass of trolley material,

$\mathrm{M}_{2}=30 \mathrm{~kg}$

Total mass,

$\mathrm{M}=\mathrm{M}_{1}+\mathrm{M}_{2}$

$=100+30=130 \mathrm{~kg}$

Total load,

$\mathrm{W}=\mathrm{M} \times \mathrm{g}$

$$
=130 \times 9.81=1275.3 \mathrm{~N}
$$

Therefor actual force acting,

$$
\begin{aligned}
& \mathrm{F} \operatorname{COS}(30)=\mathrm{W} \\
& \mathrm{F} \operatorname{COS}(30)=1275.3 \\
& \mathrm{~F}=1472.5 \mathrm{~N}
\end{aligned}
$$

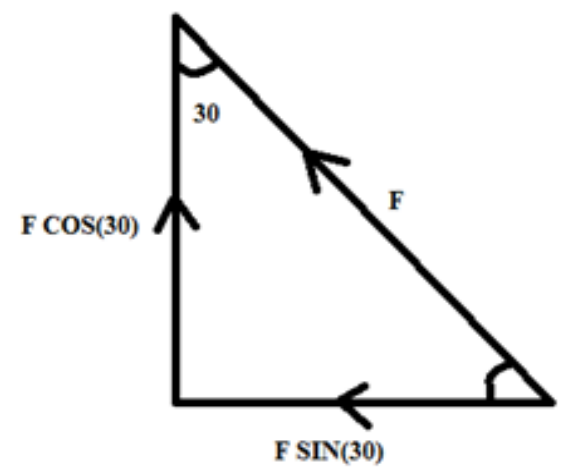

Fig. 4.1 FBD of force

Calculation of cylinder bore required, $\mathrm{F}=\mathrm{P} \times \mathrm{A}_{\mathrm{p}}$

The working pressure is taken as 30 bar, $1472.5=30 \times 10^{5} \times \mathrm{A}_{\mathrm{p}}$ $\mathrm{A}_{\mathrm{p}}=4.9086 \times 10^{-4} \mathrm{~m}^{2}$

But,

$\mathrm{A}_{\mathrm{p}}=\frac{\pi}{4} \times \mathrm{d}^{2}$

$4.9086 \times 10^{-4}=\frac{\pi}{4} \times \mathrm{d}^{2}$

$\mathrm{d}=24.95 \mathrm{~mm} \approx 25 \mathrm{~mm}$.

Calculations of design of shaft,

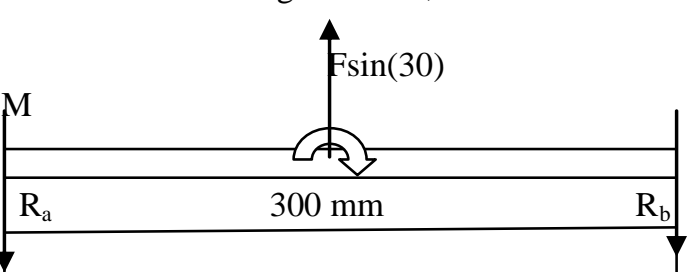

Fig.3.FBD of forces on shaft

$\sigma=\frac{\mathrm{F} \cos [(30)}{\mathrm{A}}+\frac{\mathrm{M} \mathrm{y}}{\mathrm{I}}$

$\mathrm{M}=1472 \cos (30) \times 150+1472 \sin (30) \times 20$

$=205938.4 \mathrm{~N} / \mathrm{mm}^{2}$

$$
\sigma=\frac{1623}{\mathrm{D}^{2}}+\frac{2097671}{\mathrm{D}^{3}}
$$

But we know that in compression,

$\mathrm{S}_{\mathrm{yt}}=\mathrm{S}_{\mathrm{yc}}=400 \mathrm{~N} / \mathrm{mm}^{2}$

Assume factor of safety $\mathrm{N}_{\mathrm{f}}=2$

$\sigma_{\text {allow }}=200 \mathrm{~N} / \mathrm{mm}^{2}$

$200=\frac{1623}{\mathrm{D}^{2}}+\frac{2097671}{\mathrm{D}^{3}}$

$\mathrm{D}=22 \mathrm{~mm}$

Select $\mathrm{D}=30 \mathrm{~mm}$

Therefore, diameter of shaft is $30 \mathrm{~mm}$.

\section{FUTURE SCOPE}

- Hydraulic cylinder can be used instead of pneumatic cylinder to carry heavy weight load

- Precision control over the positioning of the cylinder can be achieved by incorporating proper sensor arrangement. 


\section{CONCLUSION}

We are using the trolley with single way dumping mechanism. After literature survey it is found that the traditional method used forunloading the trolley consumes a lot of time as well as energy. It also requires high cost for setup. So these problems present in traditional method could be overcome by our proposed mechanism. After few modifications, and working on disadvantages will put this project work in the main league of use. This concept saves time and may lead to efficient working. The constructional work or the infrastructural work demands efficient and user friendly machineries which may lead to more and more use of the present project work.

\section{REFERENCES}

1. Amboji Sudhakar R., Humane Yogesh A., Chavan Rohan R., Patil Jyotsna C., Kshirsagar Prashant R., "Design and Fabrication of Three Way Tipper Mechanism", International Journal of Research in Advent Technology, , April 2014, Vol.2, No.4.

2. Ganesh Shinde, Prachi Tawele, Laukik Raut, "Design and Development of 3-Way Dropping Dumper", International Journal of Emerging Technology and Advanced Engineering, September 2014, Volume 4, Issue 9.

3. M. Abul Rahaman, R. Dharmarajan, G. Dileepan, S. Dinesh, R. Lingeshwaran, "Multi Axis Tipper", South Asian Journal of Engineering and Technology, 2016,Volume 2, (80-82).

4. Srinivasan, P. Sivanesh, G. Sugavaneswaran, K. Muthukoori, Guide. Mr. V. Prabakaran, "Downloading Mechanism Using Three Degrees of Freedom in Truck Trailer", International Research Journal of Engineering and Technology, Apr-2016, Volume.3, Issue. 4 .

5. N. Eswara Prasath, S. Shanmugam, C. Mathalai Sundaram , A. Vembathu Rajesh, "Development of Three Axis Lifting Modern Trailer", International Journal of Emerging Technology and Innovative Engineering, 5 May 2015 ,Volume 1, Issue 5.

6. Prof. Deshmukh S. A., Lonkar Pradip P., Bhong Tushar H., Kale Dadaso.B. "Three Axis Pneumatic Modern Trailer By Using Single Cylinder", International Journal of Recent Research in Civil and Mechanical Engineering, October 20015-March 2016, Volume 2, Issue 2, pp:(111-126) 